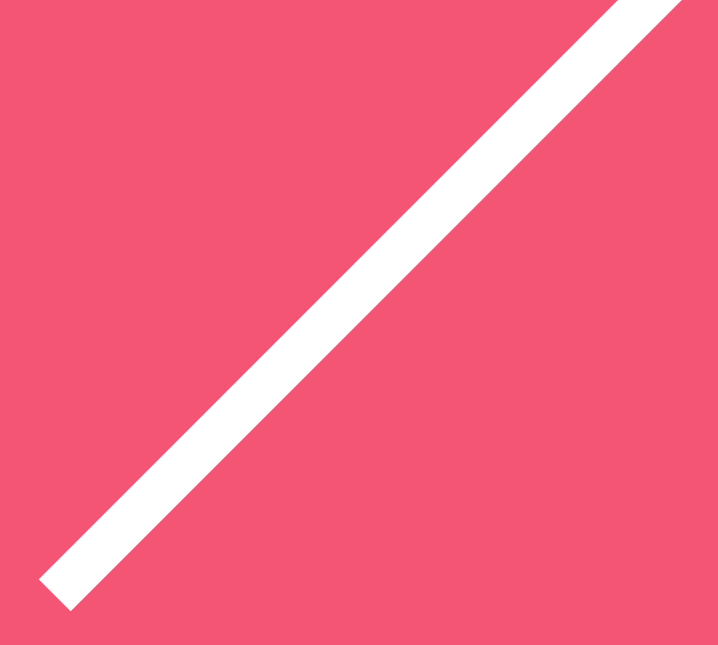

$c$

0

$\gamma$
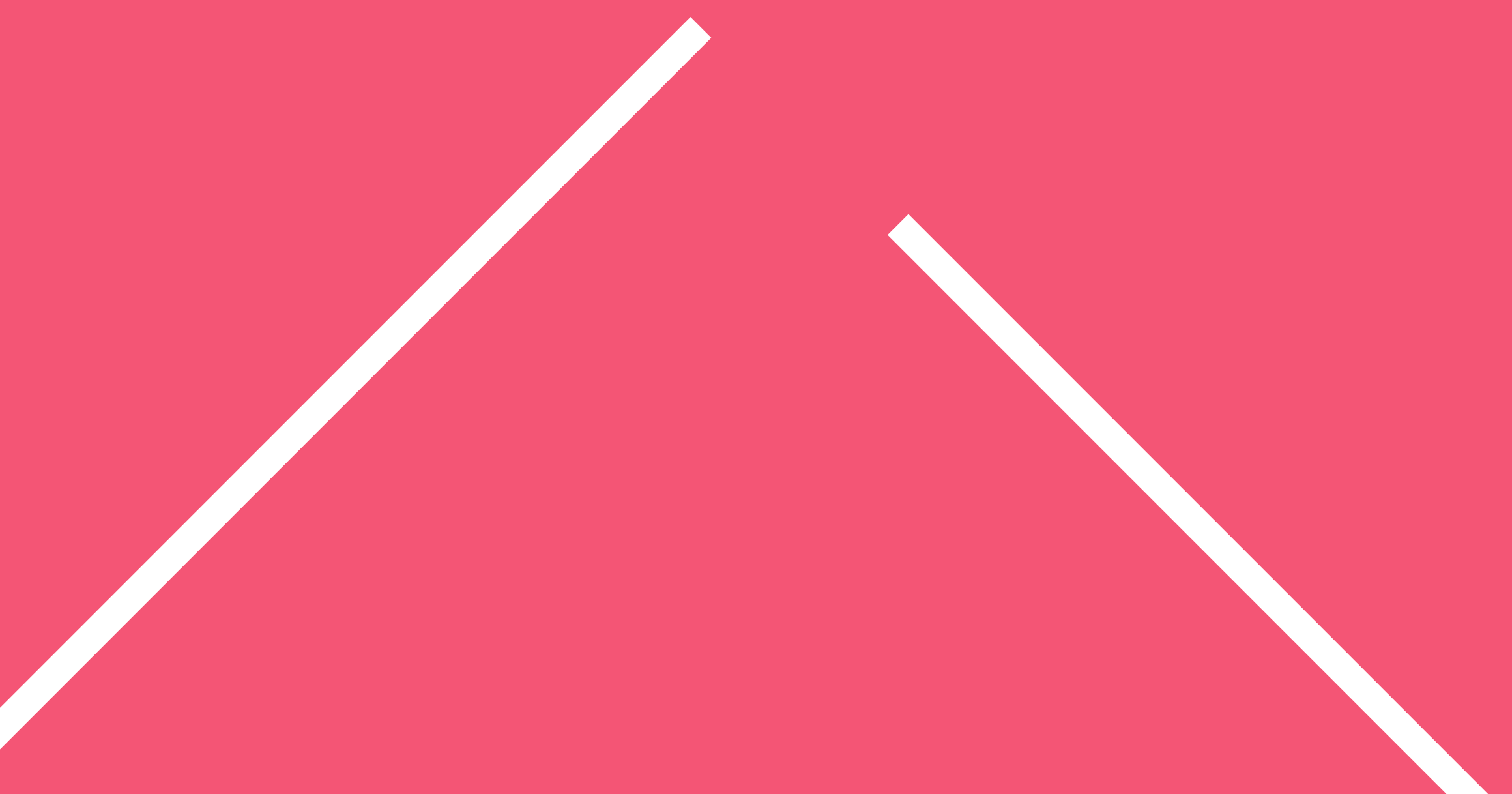

0

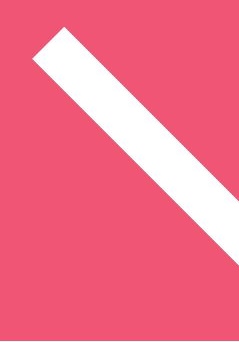




\section{Os cus do mundo}

Marcos Fábio de Faria*

* Marcos Fábio de Faria é dramaturgo do Grupo dos Dez. Professor da Universidade Federal dos Vales do Jequitinhonha e Mucuri, além de pesquisador do Núcleo de Estudos Afrodescendentes e Indígenas (NEABI-UFVJM), do Núcleo de Estudos Literatura, Artes e Saberes (NELAS-UFVJM), Guará - grupo de pesquisas descoloniais em arte contemporânea
- UDESC - e do Grup de Recerca Estudis Socials i de Gènere de Poder i la Subjectivitat (GIPIS-Universitat Autònoma de Barcelona). É editor e curador da série editorial Aquilombô. E-mail: marcosfabiodefaria@gmail.com 
O cheiro de arroto de comida azeda empesteando, à mesma vez, o início e fim do mundo fazia do ciclo do ciclo terreno uma desculpa bem meia boca e, naquela hora, em que o mundo derretia na acidez da névoa mesclada ao aquecimento global, cujos estadunidenses botavam a culpa em qualquer potência bem firmada ao leste do mundo, coisa de Rússia ou China ou uma das Coreias, diziam em rede aberta, das sociais à Fox News, antes da perda de todos, mas todos, sinais de ondas propagadas dentro e fora do globo. 0 falho, estando mais para tecnológico, porque se as ondas das estrelas seguem em vida muitos e muitos anos depois, não seria a explosão do mundo, e não do universo, que daria o fim a elas. Nenhum norte americano vivente na parte de cima do muro fronteiriço entre as Américas do Norte diria da culpa de seus eletrônicos made In qualquer nação asiática, mas das ondas apagadas por algum, como diziam, terrorista iraniano, iraquiano ou de um desses países que, provavelmente, deveriam fazer divisa com o Líbano, numa resposta irmã à explosão de nitrato de amônio do porto de Beirute. 0 cheiro do fim do mundo estava impregnado antes de tudo acabar enquanto todos esperavam a virada de tempo anunciado nas trombetas apocalípticas descritas nas Revelações de São João. Ou quase todo mundo.
Meu pai queria ser muitas coisas de pequeno, nenhuma delas seguiu adiante depois que toda a família se debandou do catolicismo e foi frequentar a igreja onde esteve o bar de um senhor conhecido daqui, que, parece, morreu só. 0 aluguel foi uma pechincha e permaneceu por anos. Cresci com a igreja dentro do bar, as paredes, as mesmas de quando existia o bar antes mesmo que eu nascesse e ainda depois de maior. Meu pai contava que antes de virar pastor e saber do mundo que viria, seus sonhos soberbos empapavam a razão e retiravam a humildade de ter a casa de Deus em qualquer lugar que estivessem alguém em oração e voltado na humildade de que a alma terrena não era verdade nessa passagem. Mas a sua humildade foi afrouxando na medida dos crescimentos, do nosso, da cidade, dos fiéis, da oratória e do patrimônio. Creio que em algum momento, confundiu as palavras livramento e arrebatamento e, no fundo de seu coração, soava obsessivo um desejo mesclado de se livrar de Deus e arrebatar a terra só para ele, sabendo que Deus queria que todos subissem ao céu e que nós, aqui, ficássemos da semente da humanidade futura.

A construção, desde que sei da minha vida, estava em função e passei a vida toda vendo a casa em reforma. Caminhões inteiros de terra saindo e caminhões chegando de tudo quanto há de material entre areia, pedra, brita, cimento, aco e chumbo. Nossa vida, baseada em economias e cupons de descontos recortados dos jornais de ontem, fizeram as mudas de roupas sempre à conta e a remendos, enquanto os sapatos reformados duravam até que a natureza resolvesse puí-los. A nossa sorte era o crescimento e torcemos para que chegássemos aos quinze com mínimo dois centímetros ao ano. Nunca foi de faltar o básico, que toda casa que é abençoada, dizia, se há de prover o alimento sagrado, que de tão sagrado e repetido, já acompanhava sozinho o caminho da colher à boca e, suspeito, pela parte de dentro ia igual. Nunca faltou, mas a conta era mais que justamente o necessário, ainda que as compras de mês fossem soberbas de coisas que nunca estiveram em nossa mesa.

Éramos cinco e todas as refeições se faziam juntos à mesa da cozinha, sempre com a mãe subservientemente servindo nossos pratos, isso depois de cozinhar e, depois, lavar todas as vasilhas. Enquanto minhas irmãs passaram a meninice limpando a casa dos pós diários, eu passei a minha peneirando e carregando areia aprendendo a fazer concreto na função de servente de pedreiro, para economizar no orçamento da obra. Todos os pedreiros que ajoelharam um aleluia ao Deus da nossa igreja, dobraram-se 
nos alicerces da nossa casa. Meu pai, mais que um bom dono de rebanho, voltou-se um excelente senhor de palavras e, com elas foi que chegou ao posto político de prefeito sem nunca deixar de lado sua vocação para bom desgraçado que não perdoou nem o dízimo dos décimos terceiros na correção monetária dos devidos vinte por cento de fim-de-ano.

Lembro-me bem de seu primeiro e último dia, quando aposentado, sair da prefeitura. Fui de menino a jovem com meu pai autoridade em tudo que é lado onde eu pisava, criando uma rede de bedéis que estavam dispostos a matar e morrer em nome do senhor meu pai ou nas funções das obras de casa. E, saindo de lá, onde nunca mais pisou, voltou-se à sua casa, esse templo de reformas infinitas que, dias depois de sua retirada da vida pública, também começou a saltar de casa para lar, pelo menos no fim das reformas e construções que chegaram em algum lugar concreto. A paz nunca esteve conosco e tampouco se arriscaria a estar no meio de nós. Saímos de uma casa em empreitadas para uma casa de sementes, de todos os tipos. Meu pai comprava milhares de sementes e as colocava em envelopes ungidos, repetindo sempre uma oração espontânea que, de tanto dizer, voltou-se ladainha.

Eu não era o primogênito, mas meu pai dizia que em caso de uma décima praga, seria meu sangue que escorria na porta de entrada da casa, já que o sangue da minha irmã era banalmente, como dizia, desperdiçado mês a mês. Ele não se envergonhava das barbaridades seguidas de versículos justificativos, propagando em recortes precisos a serventia multiplicadora das mulheres como no antes de Cristo. Mas a minha irmã pensava muito além desse nosso mundo e isso, nessa casa de leis atrasadas na Bíblia, era arriscado e, nesse caso, ela pagou com a vida. Era para ela ser virgem, gritava meu pai bem alto, a sorte é que os poucos vizinhos da nossa casa não escutaram o escândalo, mas creio que a revolta vinha do fato dela foder com um dos fiéis que vieram aqui ajudar na obra. Eu já sabia disso e guardei segredo. Mas, também, morria de vergonha de mim, porque eu a vi trepando com ele e várias vezes e cada vez eu vidrava olhando-os e, de verdade, a primeira vez que gozei foi vendo-os. E eu orava, muito, pela vergonha. Para diminuir minha culpa, ia migrando a sua buceta para outras caras, mudando as cores, cabelos, corpos era um mar de mulheres todas com a mesma buceta. Ache sempre que eram todas iguais, pois meu pai sempre dizia que mulher é tudo igual e, olhando as que me rodeavam, o único igual só poderia ser aquilo que não se vê.
A gente não dividia tantos anos assim. Eram dois, mas pareciam um infinito e ela sabia tudo e, com esse tudo, sempre fazia meu pai terminar a conversa mandando-a para o seu quarto pois enquanto ela estivesse naquele teto sagrado, comendo da comida abençoada, deveria seguir em retidão. Nessas conversas que deixei de pensar em caminhar em linha para entender que o reto era de acordo com o gosto dele. Ele desconfiava e ela sabia que ele estava por saber e fez de seu reto linha de fuga. Fugiu com o cara, mas fugiu de um canto da cidade para outro. Meu pa ficou louco e em tudo que era lugar o ódio escorria pelos cantos do seu corpo. As suas orações no culto exalavam tudo, menos qualquer palavra sagrada ainda que ele as soubesse de cor. Já entrávamos para uma semana dela sumida e dele comendo seu paradeiro pelas beiradas, porque a filha do pastor não poderia ficar rodada na boca do povo. Lá no culto, entre um aleluia sangrento e um sermão enviado dos infernos, ele gritou Efésios seis, um ao quatro. Minha mãe, esbranquiçada, caiu enquanto a igreja toda falava em línguas. Minha irmã pequena, aos prantos, gritava mamãe e eu, vendo tudo, sentia o gelo correndo tudo quanto é parte do meu corpo enquanto ele seguia pregando.

Se os planos de Deus são maiores, imagina os do diabo, que é seu concorrente? E da retidão, as linhas entortaram de tal maneira que nossa casa passou a respirar uma acidez tão pesada que nada nem ninguém parava lá dentro. E tudo, creio, começou naquela noite quando voltamos do culto, minha mãe estava fraca e nem fez nada de comida, deu jeito só de requentar o que tinha e sumiu para seu quarto. Meu pai, também não comeu e nem deixou a gente comer mandando-nos procurar nosso canto naquela ameaça que a gente já conhecia e fomos, com medo. Mais tarde, a gente acordou com os gritos da minha mãe desesperada e batendo no meu pai com força, chamando-o desgraçado. Quando ela nos viu, nos abraçou fazendo barreira contra ele e por mais que ninguém dissesse nada, já sabíamos o que tinha acontecido. 0 mundo acaba mais vezes do que damos conta de contar e vendo aquele caixão lá dentro de casa uma noite depois era a certeza que faltava. 0 primeiro velório da nossa casa, só porque na capela da cidade tinha um Deus na cruz servindo de exemplo de que o mundo acaba mesmo e o início do fim estava em nossa casa, onde as plantas morriam, as visitas eram ligeiras e aquele velório permanecia na sala. Acho que ela chegou a ver a casa terminada, não estou certo, e acho que ela até gostaria de como ficou, espero isso a cada perdão que a peço por seguir gozando com a sua buceta. 
Não me lembro de nem uma lágrima escorrida por parte de meu pai e, pelo contrário, dizia que a morte o fazia fortaleza emendando a uns versículos de Jó. Agia com uma falsa naturalidade de que o sofrimento fazia parte dessa passagem e que a isenção não estava permitida nem a Deus e essa prova do filho dado pelo mundo o elevava mais ao posto de escolhido. Com tantos anos convicto do fim do mundo, estava tudo planejado inclusive não se dispor a tornar-se sal mirando por detrás das costas enquanto haveria futuro a ser construído. Faz uns poucos anos ele disse, em público, que o fim estava próximo e os sinais estavam por todo lado e que sua casa, nossa casa, seria o abrigo do senhor e essa era a recompensa para todos os esforços de mantermo-nos onde, um dia, foi a casa do diabo e passarmos por todas provações que, mesmo más, eram divinas. Foi a única vez que o vi chorar pela filha morta e, pela primeira vez acreditei em um fim de mundo geral e que ele havia planificado tudo em todos os detalhes.

As primeiras bombas romperam o céu da América Latina ainda pela madrugada e todas distantes o suficiente de nossa casa para que não fôssemos derrubados pela irradiação que viajava por todo continente à medida que os blast iam tomando conta da nossa terra. Corremos o mais rápido possível para a construcão e minha mãe perguntava com insistência pelos demais. Meu pai disse que chegariam em breve e que estávamos preparados para isso e em comunidade. Eu sentia um cinismo em sua fala e até quis acreditar em suas palavras, mas quando entramos e ele trancou a escotilha daquele lugar que foi construído em comunidade, estava mais que certo de que seríamos quatro as sementes futuras. Olhei bem para aquele templo e em segundos todos aqueles anos de construção e reforma fizeram sentido de verdade e eu que sempre estive dentro daquela construção pensava que seria mais uma igreja, cuja estratégia subterrânea era somente um delírio de meu pai. Minha mãe, desacreditada do que estava passando, perguntava insistente pelos outros, que seriam responsabilidade, enquanto rebanho, do meu pai e quase todo rebanho, está destinado ao abate, pensei.

Estava tudo ali, tudo que era previsto para sobreviver a um fim de mundo desses de ficção. Ele explicava em tropeços as instruções, do calor que sentiríamos em alguns instantes que precisaríamos usar algumas bombonas de oxigênio caso o ar ficasse rarefeito, que a luz poderia falhar de supetão, nos primeiros dias, que conversássemos somente o estritamente necessário e que, em alguns dias, ele e eu, caso acabasse a luz, teríamos que ir para o lado de fora e que esse era um enorme perigo para nossas vidas. Eu via as suas palavras bambeando na boca e chegando com dificuldades aos meus ouvidos enquanto falava de trajes, pastilhas antirradiação, enxofre, Bíblia. Minha mãe disse que eu fiquei dias desacordado e que a luz havia caído, que passamos uma onda de calor, que nunca ninguém mais entrou ali e que viveríamos os infernos, o limbo dos vivos onde haveria de existir somente os mortos. Eu, por outro lado, tinha certeza que nunca saímos dele.

A ruindade que estava fora escapuliu-se para esse novo la enquanto o suor dos mortos de fora recobria a atmosfera numa gravidade e o fim do mundo entocou-se em qualquer fresta desse forte. Acho que enganamos o apocalipse, mas acho que, do lado de fora, era questão de tempo até que as bestas sobradas dos estrondos das bombas farejarem nosso rastro e estourasse essa arquitetura refratária em que estamos metidos. Em alguma de suas dez coroas, estaria o nosso de negadores da morte coletiva narrada para o conserto da terra. Meu pai cagou a remissão da terra achando que sua semente era a mais fértil ou qualquer coisa do tipo e, do lado de fora, baratas se alimentam da carne podre que rodeia a casa, nossa casa, acabada justo para entra no fim. Uma hora, teremos que nos alimentar das sobras de lá de fora e, ainda, correndo risco de ser alimento dos que aprenderam na hostilidade da justiça divina a sobrevivência e, também, dos que, como nós, escavaram sua sobrevivência. Talvez as ratazanas também estejam vivas, ou reproduziram do meio, do centro, do cu da terra como faziam quando o mundo era vivo.

Meu pai mudou bastante com pouco tempo de encerro, ou esteve falso tanto tempo do lado de fora. Os respiros e choros ecoavam na mesma medida se encravando na natureza daqui de dentro, estávamos dentro de uma baleia de aço que era esse estômago da terra, gerando-nos nesse processo tão natimorto de, uma hora sem data ainda, sair daqui direto para um jardim, uma cama bem feita, um café da manhã que não esteja enlatado e até as verduras chegam a fazer algo de falta. Essa porra aqui não devia nem ser chamado de mundo, nem de pedaço dele nessa deriva estanque quem nem se sabe Deus resolve. De vez em quando, algum estrondo capta a nossa presença e chacoalha a memória de que o mundo não diminui até o tamanho de nossa fortaleza serão restos do mundo digerindo qualquer ousadia de vida desse cemitério equidistante de qualquer lugar até qualquer outro lugar de lá de cima. Deitamos, limpamos, a casa e nós, desdobramos a comida para permanecermos mais e mais tempo aqui embaixo 
e lemos a Bíblia com muita constância sem saber se é manhã tarde ou noite ou quantos dias vão se passando adiante de nós.

Minha irmã menstruou hoje. Sei pelos pingos de sangue de uma limpeza às pressas no chão do banheiro, coisa que minha mãe não faria às pressas, nem meu pai em caso de corte, já que seria minha mãe que limparia a sua sujeira, como tem sido desde todos os dias desde que se casaram. Pergunto-me, às vezes, como chegaram a isso e, se algum dia, ela se questionou sobre essa luz para gentios que nos levou aos confins da terra na promessa de uma salvação. Será que ela nunca pensou que essa missão fosse uma furada? Talvez, também, o plano era diminuir todas as nações a quatro pessoas facilitando o trabalho de adiantar o outro fim do mundo. Nesse dia, meu pai nos havia preparado um sermão iniciado com o Salmo cento e oito. Iniciou a leitura do um e parou no versículo quatro. Todos nós somos parte da glória e transformamo-nos em uma única imagem, a mesma imagem, pelo espírito do senhor, disse. Busquei em minha cabeça algum trecho que fosse de reconhecimento e não alcancei nada enquanto as letras sagradas se embaralhavam em minha mente, minha mãe respondeu, com lágrimas escorrendo, a dúvida que ela sabia que era minha: Segundo Coríntios. Ela disse somente isso e foi preparar a comida.
Aprumo o corpo só o necessário e ele lamenta a saída da cama. A escuridão daqui de baixo o confunde quanto às horas dormidas e as necessárias que são vistas na boca, que responde com o pior sabor calcificando qualquer palavra para o dia. Também o nariz e a má respiração estão viciados enquanto seguimos confinados do mundo em destroços e, juntos, também ruímos qualquer coisa de família restante desde a morte de minha irmã. 0 talento doloroso da união ficou estirado lá no mundo de fora enquanto aqui vamos mantendo a tolerância de gente que divide um mesmo sangue e o mesmo rancor em uma mesma levada que infinita-se na promessa malfeita dessa arca em que, a contragosto, fomos metidos. Coloco uma oração no comando da cama até o banheiro, do banheiro à cozinha e da cozinha à mesa. Era um pedido de maldade, recorrendo o mês todo do emoçar de minha irmã na aflição do hoje à noite. Qualquer ruindade da natureza já teria suficiente jeito de adiar as razões do meu pai.

Desde que entramos aqui o turvo presentifica mais seu lugar e sabemos que essa luz artificial daqui de dentro não faz parte das coisas de Deus. Meu pai, mais que nunca, devora as escrituras enquanto elas vão se colando à ponta de sua língua e ganhando espaço de única lei aqui, nessa fundura que também imerge a nós quatro. À risca, pecados vão se justificando a mão evangélica que oscilava entre antigo e novo testamento enquanto já estávamos condenados quando meu pai desonrou as passagens de Zacarias onze, dezessete. Aqui, estáticos nessa bolha impenetrável, fugimos para o centro do senhor que, nos vigiando nas confusões de suas letras, fez da salvação a condena.

Pela primeira vez desse tempo, meu pai foi o último a se levantar e, saindo dos costumes, não dobrou seus joelhos agradecendo, não comeu nada e, com algo de irritação, gritou com a mãe empunhando-me com brutalidade para uma conversa afastada de homem para homem. Bem-aventurado são os filhos que seguem as instruções do pai, esteja atento, para que haja discernimento entre o certo e o errado. Sua fala estava calma, fria e com algo de perversidade. Nossa função estava escrita antes de nossa existência e propositada na honra da vida que nos foi permitida seguir, aqui, nesse milagre, disse. Nunca estive tão próximo de meu pai, sua imagem e semelhança estampada no reflexo de mim, um espelho futuro do que eu seria. Me vi honrando meu pai não pelo medo de ser executado, mas por ser o seu semblante daqui uns poucos anos, inclusive repetindo as mesmas palavras. Lembrei de minha irmã, de sua buceta e dos gemidos tirados das trepadas na construção da nossa casa. 
Envergonha-me, agora, mais a minha ereção, a qual tentava disfarçar diante do meu pai, que a dificuldade de colocar as genitálias dela em outro corpo.

$\mathrm{Na}$ janta, comemos juntos, a oração e a comida, e, parte da mesa engolia seco, já a outra ansiava o término e o assunto é desentocado, por parte da parte, como coisa boa, pois como não haveria de ser? Toda a dificuldade do tempo debaixo da terra, enterrados e sobrevividos nessa providência nem precisaria de convencimento para saber que estamos bastante incompletos, mas precisados de seguir adiante neste mundo por vir. Esse tempo vai emperrando e a vida ficando velha com mais velocidade e precisando da reciclagem que não se faz de outra forma que não a mirabolada pelo meu pai. Apesar dos intentos de uma conversação, nem que seja protocolar de uma família, estivemos falhos e, silenciosamente, saímos da mesa deixando pratos e restos aos cuidados da minha mãe. Cada um a seu canto, esperando em crises de ânsias a hora certa. Meu pai, ainda assim, fez questão de dizer que, não sendo eu, teria que ser ele então, portanto, melhor fosse que me aprumasse para todas as bênçãos do senhor, inclusive as que chegam por meio de provações.

Limpei-me seguindo os acordos da melhor higiene possível ali em baixo sem muito que pensar, senão no daqui a pouco quando sairemos desse buraco para fazer de volta o mundo. Coloqueime em direção ao quarto de casal, onde meus pais ficavam. Lá estavam eles, em oração, em reunião e minha irmã mais nova. Meu pais saíram da oração silenciosa ao nosso auxílio, de dois completos inexperientes. Meu pai veio até o meu ouvido enquanto minha mãe segurava as mãos da minha irmã. Ele me disse que precisaria recorrer à minha memória dos instantes que, em mim, me faria mais homem. Vendo aquela criança mais diminuta na minha frente, tive dúvidas se os propósitos do meu pai estavam mais para a história de Abraão e Sara ou a de Ló e suas filhas, enquanto a única certeza era que o que eu estava por fazer em nada era diferente do que Amnon fez a Tamar e que nossa insistência nesse buraco não daria fim ao fim do mundo. 